Multiculturalism in Classically Liberal Societies: Group Membership and Compatibility

\title{
Between Individual and Collective Justice
}

\author{
Jessica Gale ${ }^{1} \&$ Christian Staerklé ${ }^{1}$ \\ ${ }^{1}$ University of Lausanne, Switzerland
}

Reference:

Gale, J., \& Staerklé, C. (2019). Multiculturalism in classically liberal societies: Group membership and compatibility between individual and collective justice. Journal of Experimental Social Psychology, 85. https://doi.org/10.1016/j.jesp.2019.103877

Correspondence concerning this article should be addressed to Jessica Gale, Institute of Psychology, Quartier Mouline, Géopolis 5128, University of Lausanne, CH-1015 Lausanne, Switzerland. E-mail: Jessica.Gale@unil.ch 


\begin{abstract}
The degree to which classical liberal, individualist principles of Western societies are seen as (in)compatible with multiculturalism and minority rights is a key issue in diverse societies. Classical liberalism is grounded in individual justice principles, suggesting that individuals are responsible for their own fate and should be treated according to their personal characteristics, regardless of group membership. Multiculturalism, in turn, is grounded in collective justice principles, recognizing cultural differences and seeking greater equality between groups. The present research investigates how asymmetric group membership in dominant and subordinate groups shapes perceived compatibility between classical liberalism and multiculturalism. A correlational study $(N=141)$ first shows that cultural minorities perceive greater compatibility between the two justice principles compared to native majorities. A second $(\mathrm{N}=202)$ and third $(\mathrm{N}=164)$ experimental study involving the description of a fictitious society manipulated perspective-taking as a function of social status, cultural origin and numerical size of groups. The findings show that respondents taking the perspective of immigrant groups perceive greater compatibility between classical liberalism and multiculturalism as an abstract ideology compared to a native perspective, and that a low status perspective leads to greater compatibility between classical liberalism and multiculturalism as a concrete policy compared to a high status perspective. Overall, these studies suggest that membership in subordinate groups generally increases perceived compatibility between individual and collective forms of justice. Implications associated with growing civic integrationist policies in Europe are discussed.
\end{abstract}

Keywords: Social justice, multiculturalism, group membership, individual responsibility, classical liberalism 


\section{Multiculturalism in Classically Liberal Societies: Group Membership and Compatibility Between Individual and Collective Justice}

"I have finally understood what it is [sic] my problem with social justice movements: the (often implicit) idea of society based on groups against the classical liberal idea of a society based on individuals.” (Antonini, 2017, December 1)

Multiculturalism — as a political theory and a public policy—aims to foster integration of cultural minorities in the wider society by facilitating their participation in common life, by recognizing their cultural origins and differences, and by compensating their historical disadvantages (Green \& Staerklé, 2013; Kymlicka, 1995, 2001; Moghaddam, 2008). A major question surrounding multiculturalism, however, is the degree to which this group-based theory is compatible with the fundamentally individualistic orientation of classically liberal societies (Kymlicka, 1995, 2001).

Is the right to wear the Muslim headscarf a symbol of individual freedom of choice, or a sign of women's oppression under Islamic law? Are group-conscious affirmative action policies an endorsement of greater equality or, instead, a symbol of reverse-discrimination and a violation of individual responsibility principles? In this article, we argue that these alternative perspectives are shaped by belief systems associated with asymmetric group membership in dominant and subordinate groups. Existing research has amply demonstrated that ethnic minorities show greater support for multiculturalism and minority rights than national majorities (Arends-Tóth \& Van de Vijver, 2003; Dandy \& Pe-Pua, 2010; Verkuyten, 2005, 2006; Wolsko, Park, \& Judd, 2006). However, little social psychological research has analysed the degree to which members of these groups consider multiculturalism to be compatible or incompatible with classical liberal principles of individual freedom and individual responsibility. The purpose of the present research was to examine how asymmetric group membership shapes this perceived (in)compatibility. 
In the following, we first define multiculturalism as a political theory, highlighting arguments in favour or against its compatibility with the liberal state. We then discuss how belief systems associated with membership in asymmetric groups come into play, followed by three studies seeking to demonstrate how asymmetric group membership determines the degree to which individuals perceive compatibility between multiculturalism and classical liberalism.

\section{Multiculturalism and Justice Conceptions}

Multiculturalism is multifaceted. Aside from its descriptive construal denoting the presence of culturally diverse groups in society, multiculturalism can be understood as a prescriptive ideology and as a set of public policies aimed to deal with cultural diversity (Moghaddam, 2008; Sears, Citrin, Cheleden, \& van Laar, 1999), both based on collective justice principles (see Gale \& Staerklé, 2017; Green \& Staerklé, 2013). Collective justice is a form of "macrojustice" situated at the group-level (see Azzi, 1992; Brickman et al., 1981), concerned with acknowledging intergroup distinctiveness and ensuring fairness and equality between sub-groups in society (Azzi, 1998). In line with these principles, multiculturalism as an abstract ideology recognizes and values cultural differences, and as a concrete policy, compensates disadvantages associated with membership in culturally subordinate groups through affirmative action and minority rights (see Kymlicka, 2001; Moghaddam, 2008; Sears et al., 1999). Multiculturalism in its abstract form is relatively uncontroversial whereas concrete forms elicit more disagreement and opposition (Sears et al., 1999; Yogeeswaran \& Dasgupta, 2014). It is therefore imperative to consider multicultural ideology and policy separately in analyses of attitudes towards multiculturalism.

Attitudes towards multiculturalism tend to be a reflection of more general belief systems which guide peoples' thoughts about the "good society" (Staerklé, 2009; Tyler \& van der Toorn, 2013). For example, Verkuyten and Martinovic (2006) show that support for 
multiculturalism is negatively correlated with individualism, operationalized as the belief that people are responsible for their own fate. This belief is linked to individual or "micro" forms of justice and is prevalent in Western liberal societies where societal norms attribute (lack of) achievements more easily to personal dispositions than to external situations, group affiliations, or collective disadvantages (Azzi, 1998; Brickman et al., 1981; Ross, 1977; Staerklé, 2009).

Classical liberalism, rooted in the enlightenment philosophies of John Locke and Adam Smith, is at the core of these societal norms, encompassing not only individual autonomy and responsibility, but also capitalist free-market ideology and the individual right to property (see for example MacIntyre, 1981). Rawls' (1971) concepts of the "veil of ignorance" and "original position" also denote principles of classical liberalism as they prescribe the disregard of structural inequalities in order to allow equal treatment of all individuals according to their personal characteristics. Given the pervasiveness of these societal norms (Deschamps, 1982), how can multiculturalism, with its emphasis on groups, complement rather than contradict the taken-for-granted individualism of classically liberal societies? While social psychology has scarcely addressed this question, such a debate has a long history in political theory.

\section{Multiculturalism: Union or Separation Between Individual and Collective Justice}

Some theorists argue that multicultural principles and policies complement classical liberal theory. Towards the end of the $20^{\text {th }}$ century, a "communitarian critique of liberalism" emerged in North America in which (classical) liberalism ${ }^{1}$ was criticized for its universal and "atomistic" nature, conceptualizing individuals as self-sufficient and living in a social vacuum. Such critics called for greater acknowledgement of group membership as a

\footnotetext{
${ }^{1}$ We use "liberalism" in the sense of political theory (e.g., Kymlicka, 1995; Mouffe, 1992) to refer to classical liberal enlightenment philosophy based on the principle of individual autonomy. It should not be confounded with "liberalism" (as opposed to "conservatism") in the ideological and party politics sense, used mainly in the context of North American politics.
} 
foundation of self-esteem, personal development and sense-making (MacIntyre, 1981; Sandel, 1982; Taylor, 1985; Walzer, 1990). At an abstract level, valuing group-based diversity became a strategy to ensure positive self-feelings and secure identities for all members of society (Verkuyten, 2006). At a concrete level, minority rights and affirmative action policies acknowledged that minorities can be exposed to injustices related to language, politics and power, even when their individual rights are respected. Kymlicka $(1995,2001)$ highlights how multicultural policies protect minorities from oppression of the state, heeding and legitimizing their claims and supplementing basic rights guaranteed to all individuals in liberal societies. From this perspective, multiculturalism unites individual and collective justice.

Other theorists however argue that multicultural principles and policies are in contradiction to liberal theory. One argument is that multiculturalism's interventionist approach is incoherent with liberalism's laissez-faire principle (see Kukathas, 2003). Another is that multiculturalism's recognition of cultural differences reinforces the group-based divides it seeks to reconcile by encouraging essentialization and spatial segregation between groups of different cultural backgrounds (see Barry, 2001; Koopmans, 2008). Sears et al. (1999) warn of "ethnic balkanization" whereby multiculturalism increases intergroup conflict through "heightened ethnic consciousness and antagonism towards other groups" (p. 36; see also Brewer, 1997). These arguments imply negative interdependence between multiculturalism and liberalism. From this perspective, multiculturalism is associated with a separation between individual and collective justice.

In social psychology, most studies have followed the logic of incompatibility by showing that individual justice (e.g., system-justifying meritocratic principles) is perceived as irreconcilable with collective justice (e.g., affirmative action in favour of social change; see Bobocel, Son Hing, Davey, Stanley, \& Zanna, 1998; Brickman et al., 1981; see also Son Hing et al., 2011, for nuances). Indeed, one may argue that this incompatibility between individual 
and collective justice is a hallmark finding of research on attitudes towards affirmative action and other minority-targeted policies. In the present paper we argue on the contrary that it is precisely this incompatibility that needs to be unpacked, by examining the social conditions under which individuals consider these two basic forms of justice to be compatible or not. We suggest that a key moderator of perceived compatibility is asymmetric group membership, which shapes perceptions of social reality in line with one's position in the social hierarchy (see Bourdieu, 1979; Staerklé, 2009).

\section{Asymmetric Group Perspectives on Justice and Multiculturalism}

We argue that compared to dominant groups, cultural minority and other subordinate groups have a fundamentally different outlook on justice and multiculturalism that ultimately leads them to perceive individual and collective justice principles as being relatively compatible. Existing research confirms that ethnic minorities generally prefer multiculturalism as an integration policy whereas national majorities generally prefer individual justice-based policies such as assimilationism or other difference-blind policies (see Arends-Tóth \& Van de Vijver, 2003; Ryan, Hunt, Weible, Peterson, \& Casas, 2007; Verkuyten, 2005, 2006; Wolsko et al., 2006). This group-based distinction is often explained by both identity-related and instrumental motives, since multicultural policies aim to promote social recognition of cultural minority groups, to allow for their cultural maintenance, and to improve their position as a group in the social hierarchy (see Verkuyten, 2005, 2006). This research explains why cultural minorities prefer collective justice compared to national majorities. But it does not explain differences in perceived compatibility between individual and collective justice principles which, we argue, are rooted in different modes of collective self-definitions for subordinate and dominant group members.

Indeed, subordinate group members tend to identify more readily with their group compared to dominant group members who tend to self-identify as individuals (Deschamps, 
1982; Lorenzi-Cioldi, 1998; Simon, Aufderheide, \& Kampmeier, 2001). Such a trade-off between individual and collective forms of self-definitions is highlighted by Optimal Distinctiveness Theory (Brewer, 1991) that suggests that the groups with which people identify most strongly are those that provide an "optimal balance" between inclusion and distinctiveness needs (see also Hornsey \& Jetten, 2004). This optimal balance is not only conditioned by asymmetric group membership, but it also shapes conceptions of individual and collective justice.

Azzi (1998), for example, highlights that collective justice is especially of concern when group membership is salient. This tends to be more often the case for cultural minority and other subordinate groups, creating a sense of (in-group) inclusion and (intergroup) distinctiveness, compared to national majority and dominant groups. At the same time, members of cultural minority groups are acutely aware of the individualistic nature of Western society (Sampson, 1988): Being fully accepted in a Western society implies identifying with principles of individual justice as well.

This difference in collective self-definitions therefore has deep roots in the ideological makeup of society. Collectively defined cultural minorities and other subordinate groups see themselves as being more distant from an individualist "point of reference [that] tends to define those who are owners of material and symbolic capital"' (Deschamps, 1982, p. 88), but at the same time they aspire to get closer to this point of reference while still remaining sensitive to intergroup (Simon et al., 2001) and collective justice concerns. Research indeed shows that subordinate groups with a migration background engage in political claims for their group especially when they identify simultaneously with their own as well as the dominant group's values (see Simon, 2011; Simon \& Ruhs, 2008). Their concern for collective justice is therefore anchored in individual justice principles. 
Dominant group members, in turn, have a more straightforward balance between their needs for inclusion and distinctiveness through their very membership in a dominant group defined by individualist norms (Hornsey \& Jetten, 2004; Lorenzi-Cioldi, 1998). They thus tend to self-categorize as individuals, show "mindlessness" about group belongingness (see Iacoviello \& Lorenzi-Cioldi, 2015; Simon et al., 2001), and demonstrate concern for individual rather than for collective justice (Azzi, 1992, 1998; Gale \& Staerklé, 2017). Of course, consciousness of their advantages can increase their collective awareness and lead to greater intergroup guilt (Powell, Branscombe, \& Schmitt, 2005; see also Moscovici \& Pérez, 2007), anger and support for initiatives seeking to compensate disadvantaged group members (Leach, Iyer, \& Pedersen, 2006). But in line with the general assumption of a fundamental incompatibility between individual and collective justice, this greater collective awareness for dominant group members is thought to imply a distancing from individualist beliefs, suggesting that support for multiculturalism would weaken as individualist beliefs increase. Overall, then, this literature leads us to believe that not only is collective justice more salient for subordinate groups, but also that individual and collective forms of justice are more compatible, or at least less incompatible, for subordinate than for dominant groups.

\section{Dimensions of Intergroup Asymmetry}

In most studies on intergroup differences in multicultural attitudes, authors distinguish between Whites and other ethnicities (see for example Ryan et al., 2007; Wolsko et al., 2006), or between national majorities (e.g., Dutch or natives in general) and cultural minorities (e.g., Turkish-Dutch or immigrants in general; see for example Arends-Tóth \& Van de Vijver, 2003; Dandy \& Pe-Pua, 2010; Verkuyten, 2005, 2006; Verkuyten \& Martinovic, 2006). These natural groups, however, may confound different dimensions defining asymmetric intergroup relations, in particular socio-economic status, cultural origin and numeric group size, each of which can potentially intervene in shaping justice beliefs. To our knowledge, no studies have 
yet compared these differing asymmetric characteristics when studying attitudes towards multiculturalism. A further objective of our research was thus to determine the specific dimensions of asymmetric group membership that might explain the extent to which multiculturalism, as an ideology and policy, is perceived as (in-)compatible with classical liberalism.

\section{The Present Studies}

The purpose of the three present studies was threefold. Study 1 investigated whether the well-established difference between national majorities and cultural minorities in support for multiculturalism was moderated by beliefs in individual responsibility, a key dimension of individual justice and classical liberalism. Study 2 sought to replicate this analysis experimentally and to disentangle specific features associated with these asymmetric groups. Finally, Study 3 sought to replicate our findings with alternative, prescriptive measures of classical liberalism. Our general hypothesis was that asymmetric group membership and belief in classical liberalism would interact such that subordinate group members perceive greater compatibility between multiculturalism and liberalism compared to dominant group members. We report all measures, manipulations, and exclusions in these studies.

All studies were conducted in Switzerland, a country where national policy favours individual responsibility and assimilation of newcomers, putting little or no emphasis on their cultural maintenance (see Koopmans, 2010). In other words, Swiss society is firmly grounded in classical liberal norms of individual justice.

\section{Study 1}

First, a correlational study was conducted comparing native majorities and cultural minorities in the degree to which they considered multiculturalism and the belief in individual responsibility to be complementary or incompatible. Multiculturalism was operationalized in two ways: As an ideology that recognizes and values cultural groups and differences, and as 
an affirmative action policy that seeks to compensate disadvantages associated with membership in cultural minority groups.

Our first hypothesis was that cultural minorities would support both facets of multiculturalism significantly more strongly than native majorities. Our second hypothesis was that group membership and belief in individual responsibility (as the measure of classical liberalism) would interact to predict support for multicultural ideology and policy:

Differences between cultural minorities and natives should be greater when their belief in individual responsibility is strong (2a), and such a belief should be negatively associated with support for multiculturalism only for natives (2b), but not for cultural minorities. Given multiculturalism's multifaceted yet "unidimensional" nature (i.e., based on the same underlying collective justice principles; see also van de Vijver et al., 2008, p. 102), we expected these effects to be the same for both ideology and policy. However, policy would be generally less supported than ideology (see Sears et al., 1999; Yogeeswaran \& Dasgupta, 2014).

\section{Method}

Participants. Participants included 141 respondents recruited through an online snowball technique in the French-speaking part of Switzerland. Analyses were conducted only after all participants were recruited. ${ }^{2}$ Age ranged from 18 to $68(M=26.86, S D=10.56$; 1 non-response) and most were female $(69.5 \%, N=98)$. The majority had solely Swiss nationality $(64.5 \% ; N=91)$, while the remainder were either Swiss with dual (or triple) nationality $(25.5 \% ; N=36)$, or non-Swiss $(10 \% N=14)$. Given their migration ancestry or experience with alternative cultural norms, respondents with dual nationality and non-Swiss nationality were both considered to be sensitive to questions related to minority cultural

\footnotetext{
${ }^{2}$ Power analyses were conducted using G*Power 3.1, based on previously documented differences between dominant (white, national majority) and subordinate (ethnic minority) groups on support for multiculturalism. Effect sizes $(d)$ ranged from .47 (Wolsko et al., 2006, Study 1) to 1.99 (Verkuyten, 2005, Study 4). To replicate these effects for .80 power level, a sample of 10 (5 dominant, 5 subordinate) to 118 (69 dominant, 49 subordinate) participants was needed.
} 
status. National majorities therefore comprised participants with only Swiss nationality (coded 1), and cultural minorities included dual or triple as well as non-Swiss citizens (coded -1$){ }^{3}$

Procedure and materials. All participants filled out an online questionnaire including sociodemographic characteristics and the following measures ranging from 1 (strongly disagree) to 6 (strongly agree). ${ }^{4}$

Belief in individual responsibility was assessed using a 4-item scale $(\alpha=.73, M=$ 3.13, $S D=0.94$; centred for analyses) originally developed by Major et al. $(2002)^{5}$, adapted and translated into French. Items included, "Switzerland is a society where each individual can attain a better position in society," "Most people who do not progress should not blame the system; they are responsible themselves," "Some people cannot manage to progress in society because of social inequalities" (reverse-coded), "Some people struggle to attain a better position in society because of their origins" (reverse-coded). High scores indicated a strong belief in individual responsibility for progress, and low scores indicated a belief that structural inequalities can inhibit progress.

Support for multicultural policy was assessed with three items $(\alpha=.78, M=3.23, S D$ $=1.20$ ) referring to affirmative action policies in the domains of education, employment and government: "Schools having a large proportion of children from cultural minority groups should receive special funding in order to guarantee conditions that are favourable to

\footnotetext{
${ }^{3}$ Cultural minorities' ancestries were mostly Western European (76\%; 52\% neighbouring Switzerland) and North American (6\%). Analyses were also conducted with the three citizenship categories kept separate using orthogonal contrast coding. Interpretation of results remained identical (see supplementary materials).

${ }^{4}$ The following additional measures were included in the study: Social Dominance Orientation (6 items), Right Wing Authoritarianism ( 3 items), National and cultural identity (4 items each) and distractors from support for multiculturalism items ( 7 items; worded similarly but with emphasis on justice between individuals instead of groups). These measures were used to establish construct validity of the indicators measuring support for multicultural ideology and policy.

${ }^{5}$ This variable was originally named "individual mobility" and "endorsement of meritocracy" (see also McCoy \& Major, 2007; Wiley, Deaux, \& Hagelskamp, 2012). However, we chose "belief in individual responsibility" for the purpose of our study because the items measure this key dimension of liberalism. Meritocracy, in the literature, is often associated with the idea that hard work brings success and that positive outcomes are contingent on deservingness; dimensions which are not present in this measure. Individual responsibility for upward mobility and perceived permeability of group boundaries, however, represent fundamental components of the belief in classical liberalism.
} 
success," "In order to guarantee diversity between employees, some job posts should be reserved for qualified members of minority groups," and "The government should show an example and hire more members of cultural minority groups" (see Berry \& Kalin, 1995). These items refer to the concrete facet of multiculturalism that is concerned with both recognizing groups and decreasing inequalities.

Support for multicultural ideology was assessed with four items $(\alpha=.76 ; M=4.35$, $S D=0.95$ ) inspired from existing research (see Berry \& Kalin, 1995; Guimond, de la Sablonnière, \& Nugier, 2014; Ryan et al., 2007) and constructed to represent the abstract idea that cultural origins and group differences should be recognized and valued. Item examples include, "Cultural affiliations are a precious distinction between individuals that should be valued," and "In general, cultural differences should be celebrated."

\section{Results}

Data analysis was carried out using SPSS, version 25. Descriptive statistics and correlations were assessed first, followed by hypothesis testing. In order to retain the complete sample of respondents and to prevent a reduction in statistical power, Maximum Likelihood (ML) estimation method was applied for missing cases of items representing belief in individual responsibility and support for multicultural ideology and policy (4.0\% missing data, Little's MCAR test, $\left.\chi^{2}(191)=195.28, p=.401\right)$.

Descriptive statistics and correlations. The means presented above show that in general, participants had a rather weak belief in individual responsibility, demonstrating awareness that structural inequalities can hinder one's progress in society. Moreover, they tended to be rather supportive of multicultural ideology, but significantly less so of its policy, $t(140)=10.78, p<.001, d=1.82$, consistent with our expectations. While the two facets of multiculturalism were positively correlated $(r=.36, p<.001)$, ideology was not significantly 
associated with the individual responsibility belief $(r=-.16, p=.053)$, and policy was negatively correlated with the individual responsibility belief $(r=-.46, p<.001)$.

Hypothesis testing. For hypothesis testing, two two-step hierarchical regressions were conducted with each facet of multiculturalism as the outcome variable. To test our first hypothesis, predictors in step 1 included national citizenship and individual responsibility belief as main effects. To test our second hypothesis, the interaction between citizenship and individual responsibility belief was entered in step 2 .

Our first hypothesis was rejected in both models. While the omnibus tests revealed significance in step $1, F(2,138)=19.08, p<.001, R^{2}=.22$ for multicultural policy, $F(2,138)$ $=3.29, p=.040, R^{2}=.05$ for multicultural ideology, no main effects of citizenship were found. Indeed, citizenship did not significantly predict support for multicultural policy, $B=-$ $0.11, S E=0.10,95 \%$ CI $[-0.30,0.08], t(138)=-1.17, p=.243$, nor ideology, $B=-0.14, S E=$ $0.08,95 \%$ CI $[-0.31,0.03], t(138)=-1.65, p=.102, d=0.28$, although results were in the expected direction.

Consistent with our second hypothesis, the interaction effect of citizenship by individual responsibility belief accounted for a significant increase in explained variance in step $2, \Delta F(1,137)=5.47, p=.021, \Delta R^{2}=.03$ for policy, $\Delta F(1,137)=14.10, p<.001, \Delta R^{2}=$ .09 for ideology. This significant interaction effect was negative in both models, $B=-0.25, S E$ $=0.11,95 \% \mathrm{CI}[-0.46,-0.04], t(137)=-2.34, p=.021, d=0.40$ for policy, $B=-0.34, S E=$ $0.09,95 \%$ CI $[-0.52,-0.16], t(137)=-3.76, p<.001, d=0.64$ for ideology. Figure 1 illustrates the decomposition of these interactions, including unstandardized coefficients (and standard errors) of simple effects. 

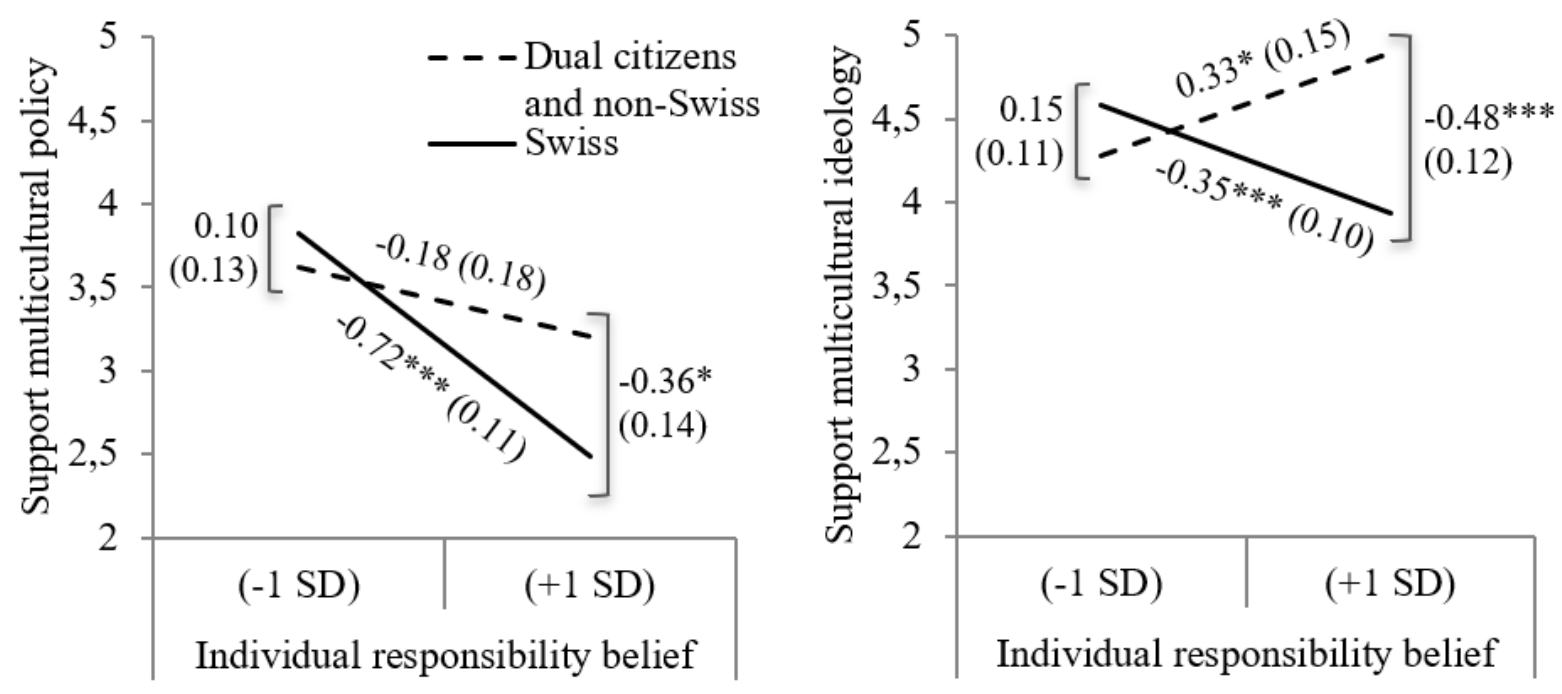

Figure 1. Perceived (in)compatibility between individual responsibility and multiculturalism by citizenship (Study 1). Numbers represent unstandardized coefficients (and standard errors) of simple effects.

$* * * p<.001, * p<.05$.

When predicting support for multicultural policy, results were consistent with hypotheses $2 \mathrm{a}$ and $2 \mathrm{~b}$. Simple effects showed that when the belief in individual responsibility was stronger $(+1 S D)$, native Swiss participants supported multicultural policy significantly less than participants with other nationalities (H2a), 95\% CI [-0.64, -0.08], $t(137)=-2.55, p=$ $.012, d=0.44$. When a belief in individual responsibility was weaker (or awareness of structural inequalities was stronger, $-1 S D)$, no significant difference was found between Swiss and other nationalities, $95 \%$ CI $[-0.16,0.36], t(137)=0.78, p=.435$. Moreover, for native Swiss, a stronger belief in individual responsibility was associated with significantly less support for multicultural policy (H2b), 95\% CI [-0.94, -0.49], $t(137)=-6.32, p<.001, d$ $=1.08$. For participants with other nationalities, support for multicultural policy was similar regardless of degree of individual responsibility belief, 95\% CI [-0.57, 0.13], $t(137)=-1.23, p$ $=.219$. In sum, individual responsibility and multicultural policy were negatively linked and thus considered incompatible for native Swiss citizens. However, there was no link between 
the two for participants with other nationalities, and the interaction effect suggested they perceived significantly less incompatibility between the two.

When predicting support for multicultural ideology, simple effects were similar. When a belief in individual responsibility was stronger $(+1 S D)$, native Swiss participants supported multicultural ideology significantly less than participants with other nationalities (H2a), 95\% CI $[-0.72,-0.24], t(137)=-3.96, p<.001, d=0.68$. When a belief in individual responsibility was weaker (-1 SD), no significant differences were found between native Swiss and other nationalities, 95\% CI [-0.06, 0.37], $t(137)=1.39, p=.166$. For native Swiss, a stronger belief in individual responsibility was again associated with significantly less support for multicultural ideology (H2b), 95\% CI [-0.54, -0.16], $t(137)=-3.58, p<.001, d=0.61$. However, for participants with other nationalities, a stronger belief in individual responsibility was associated with significantly greater support for multicultural ideology, 95\% CI [0.03, 0.63], $t(137)=2.18, p=.031, d=0.37$. In sum, individual responsibility and multicultural ideology were incompatible for native Swiss citizens, but compatible for those with other nationalities.

\section{Discussion}

Results from this correlational study provide preliminary evidence that national majorities and cultural minorities differ in the degree to which they perceive multiculturalism (collective justice) as compatible with liberalism (individual justice). Multiculturalism was defined both as an abstract ideology and as a concrete policy. The non-significant main effect of citizenship (H1) suggests that native Swiss majorities and minorities with other national heritage did not differ in their support for either facet of multiculturalism. This result was unexpected and can be explained by the fact that in French-speaking Switzerland where data were collected, public opinion tends to be relatively supportive of cultural minorities in comparison to the Swiss German majority region (Manatschal, 2011). 
The significant interaction terms $(\mathrm{H} 2)$, however, show that differences between national majorities and cultural minorities were only significant when a belief in individual responsibility was strong $(\mathrm{H} 2 \mathrm{a})$ and that national majorities considered multiculturalism to be incompatible with liberalism $(\mathrm{H} 2 \mathrm{~b})$, while cultural minorities perceived greater compatibility (or no link between the two). These results suggest that the distinction between cultural minorities and national majorities in support for multiculturalism so widely demonstrated in the literature (see Arends-Tóth \& Van de Vijver, 2003; Dandy \& Pe-Pua, 2010; van de Vijver et al., 2008; Verkuyten, 2005, 2006; Wolsko et al., 2006) can be explained by the degree to which multiculturalism, based on collective justice principles, is perceived as complementary or incompatible with the dominant societal norm of individual justice. In order to confirm this interpretation and to compensate for the limitations of Study 1 (convenience sample, relatively small minority group, pooling of non-Swiss and dual citizenship respondents into a single cultural minority group), a second, experimental study was designed. This study also sought to determine the actual criteria of asymmetric groups that lead their members to perceive (in)compatibility between multiculturalism and classical liberalism.

\section{Study 2}

Study 2 involved a realistic description of a fictitious society (see Azzi, 1992; Jetten, Mols, \& Postmes, 2015). This approach allowed us to distinguish between the different asymmetric group types, all fabricated and "unknown" to participants. It also allowed us to maintain a social context similar to the one participants experienced in their daily lives, allowing them to transpose their assumptions and conceptions of the world onto the fictitious situation presented to them (Bruckmüller \& Abele, 2010; Conway, Pizzamiglio, \& Mount, 1996).

The experimental design aimed to disentangle social status (high/low), cultural origin (native/immigrant ancestry) and numerical size (majority/minority) as criteria of asymmetric 
groups. Prior research has studied ingroup favouritism and outgroup derogation distinguishing asymmetric groups according to status, power and size (see Sachdev \& Bourhis, 1991; Simon et al., 2001). Status manipulations in such studies generally relied on prestige and esteem, assigning participants to groups according to their alleged creativity (Sachdev \& Bourhis, 1991) or artistic taste (Lücken \& Simon, 2005). Since national majorities and cultural minorities generally differ in terms of access to cultural and material resources (see Simon \& Oakes, 2006), we defined status in terms of social standing by differentiating groups based on education and career success or failure.

We expected that perceived compatibility between multiculturalism and individual responsibility would depend on the interplay between the specific criterion of intergroup asymmetry (origin, status and size) and the abstract vs. concrete nature of multiculturalism. We reasoned that since concrete (e.g., affirmation action-type) policies of multiculturalism were devised not only to enhance cultural recognition, but also to decrease social inequalities between subordinate and dominant groups (Kymlicka, 1995, 2001; Moghaddam, 2008), social status differentials should play a greater role in shaping perceived compatibility than the other two criteria (origin and size; H1). Hence, only high status group members should perceive incompatibility between multicultural (affirmative action) policy and individual responsibility, and low status group members should not. Given the dual focus of multicultural policies on recognition and inequality reduction, however, we did not discount the possibility that status interacts with origin to reveal more nuanced effects.

Conversely, we expected that cultural origin should be a relatively more important predictor of perceived compatibility between multicultural ideology and individual responsibility compared to status and size (H2), because multicultural ideology abstractly values group-based cultural differences. We therefore expected that native group members 
would perceive incompatibility between multicultural ideology and individual responsibility (H2a), while immigrant group members would perceive compatibility between them (H2b).

For all hypothesis tests, differences between numerical minorities and majorities were controlled for.

\section{Method}

Participants. Participants included 202 students in an introductory social psychology course at a university in French-speaking Switzerland. This sample size was determined before data analysis. ${ }^{6}$ Age ranged from 17 to $45(M=20.58, S D=3.23 ; 7$ non-response), with $98 \%$ under 28 years old. Participants were predominantly women $(71 \%, N=143 ; 8$ nonresponse) and $49 \%$ were solely Swiss $(N=99)$. The remainder were Swiss with dual (or triple) nationality $(33 \% ; N=67)$ or non-Swiss $(15 \%, N=30 ; 6$ non-response).

Procedure and materials. During class, participants filled out a questionnaire comprised of the following experimental manipulations and measures.

Belief in individual responsibility. First, participants filled out the same 4-item measure described in Study $1(\alpha=.61, M=3.13, S D=0.84)$.

Experimental design. Each participant was then randomly assigned to one of eight conditions, according to a 2 (status: high vs. low) x 2 (origin: native vs. immigrant) x 2 (size: majority vs. minority) experimental design. In each condition, participants read a scenario about life on an island named Ral inhabited by two groups: the Kaldan $(N=104)$ and the Felorese $(N=98)$. Participants were asked to imagine themselves as a member of one of the two groups. The Kaldan were of high social status, with more jobs and greater academic success, whereas the Felorese were of lower social status, struggling to find jobs and with weaker academic success (first experimental condition: status). Participants also read about

\footnotetext{
${ }^{6}$ Based on interaction effects from Study 1, a power analysis conducted using G*Power 3.1 showed that 80 participants were needed to replicate the medium-sized effect $(d=.64)$ on support for multicultural ideology, while 200 were needed to replicate the smaller-sized effect $(d=.40)$ on multicultural policy (for .80 power).
} 
the origins of their group, either having ancestors who immigrated to the island over 100 years ago following a natural disaster on their island of origin $(N=99)$, or having ancestors whose origins were native to Ral since the beginning of time $(\mathrm{N}=103$; second experimental condition: origin). ${ }^{7}$ Their group was either a numerical minority with 50000 inhabitants $(N=$ 100) or a numerical majority with 300000 inhabitants on the island $(N=102$; third experimental condition: size; full text in supplementary materials).

Support for multicultural policy and ideology. At the end of the scenario, participants read that the governor of an adjacent island had recently suggested to the leaders of Ral to implement policies seeking to improve living conditions of the two groups on the island. Participants were asked to respond to a survey, conducted by the government of Ral, requesting the population's opinion towards the proposed policies and measures. As members of the assigned groups, participants were asked to indicate their degree of agreement with the same items used in Study 1, assessing their support for multicultural policy (3 items; $\alpha=.62$, $M=3.62, S D=1.05)$ and ideology $(4$ items; $\alpha=.64, M=4.12, S D=0.90){ }^{8}$

Participants then responded to a manipulation check composed of the three following sections.

Perceived privilege was measured by four items $(\alpha=.83)$. Two items assessed privilege, for example, "I feel privileged because I am a Kaldan [Felorese]," and two items assessed disadvantage (reverse-coded), for example, "I feel disadvantaged because I belong to the Kaldan [Felorese] group.” All were coded on a 6-point scale ranging from 1 (strongly

\footnotetext{
${ }^{7}$ Having ancestors living in a country for over 100 years does not imply that their offspring are immigrants, per $s e$, as well. However, we use the label "immigrant" to acknowledge the salient immigration background (and thus cultural minority status relative to natives) of members of this group. This distinction is relevant in the European context, in which this study was conducted. In Europe, the native, national majority group is generally dominant relative to groups with an immigration background, unlike in settler contexts where natives (i.e., aboriginals) form subordinate groups and where "immigration background" has a different meaning. ${ }^{8}$ The same distractors in Study 1 were included in Study 2 (7 items; worded similarly as support for multiculturalism items, but with emphasis on individuals rather than groups).
} 
disagree) to 6 (strongly agree). High scores indicated perceived privilege, low scores indicated perceived disadvantage.

Recall and understanding of the text was assessed using three pairs of items coded on a 6-point scale ranging from 1 (not at all) to 6 (completely). One pair referred the numerical majority/minority status of the participant's group: "My group is larger in numbers than the other," and, "My group constitutes less than half the population of Ral island" $(r=-.85, p<$ .001). Another tapped into their native/immigrant status: "On Ral island, my group is native," and, "My group took up residence on Ral island following a natural catastrophe on our island of origin" $(r=-.71, p<.001)$. The last pair referred to their social status, represented by their access to jobs: “Almost all members of my group have a job," and, "Members of my group sometimes have trouble finding work" $(r=-.85, p<.001)$. Each pair was collapsed into a single score after the second item was reverse-coded. A high score indicated majority status, native status, and high social status, respectively.

Difficulty of the exercise was measured by two items coded on a 6-point scale ranging from 1 (not at all) to 6 (completely): "To what extent was it easy to put yourself in the place of a member of the Kaldan [Felorese] group?" and, "To what extent did you find the questions difficult to respond to?" These items were treated separately $(r=-.38, p<.001)$. Participants were then asked to reflect on their experience in a section where they could comment freely.

Questions regarding sociodemographic characteristics were included at the end of the questionnaire.

\section{Results}

Manipulations were checked first, followed by descriptive statistics and finally hypothesis testing. Maximum Likelihood (ML) estimation method was applied for missing cases of all items $(0.93 \%$ missing data) except sociodemographic ones. In order to control for characteristics representing membership in real asymmetric groups, all analyses were also 
performed controlling for citizenship, gender and age. Unless otherwise stated (in supplementary materials), no links were found between these characteristics and any conditions or measures in the study.

\section{Manipulation checks.}

Perceived privilege. In a three-way ANOVA, tests of between-subjects effects showed that participants assigned to the high status group $(M=4.74, S E=0.09)$ felt significantly more privileged than those assigned to the low status group $(M=3.03, S E=0.09), F(1,194)$ $=182.72, p<.001, \eta_{\mathrm{p}}{ }^{2}=0.49$, and natives of the island $(M=4.01, S E=0.09)$ felt more privileged than immigrants $(M=3.76, S E=0.09), F(1,194)=3.88, p=.050, \eta_{\mathrm{p}}{ }^{2}=0.02$. Majority members $(M=4.00, S E=0.09)$ did not feel significantly more privileged than minority members $(M=3.77, S E=0.09), F(1,194)=3.21, p=.075, \eta_{\mathrm{p}}^{2}=0.02$.

Recall and understanding of the text. A three-way MANOVA showed that low status group members $(M=1.82, S E=0.08)$ recognized their lower status in comparison to high status group members $(M=5.04, S E=0.08), F(1,194)=755.47, p<.001, \eta_{\mathrm{p}}{ }^{2}=0.80$. Immigrants $(M=1.76, S E=0.11)$ recognized their immigrant status in comparison to natives $(M=5.22, S E=0.10), F(1,194)=514.86, p<.001, \eta_{\mathrm{p}}{ }^{2}=0.73$. Minority members $(M=1.58$, $S E=0.11)$ recognized their numerical minority status in comparison to majority members $(M$ $=5.43, S E=0.11), F(1,194)=788.15, p<.001, \eta_{\mathrm{p}}^{2}=0.80$.

Difficulty of the exercise. A three-way MANOVA predicting the two measures of perceived easiness and difficulty of the task showed no significant differences between the three manipulations.

Descriptive statistics and correlations. The means presented in the methods section for the overall sample show that participants were generally aware of structural inequalities in society and supportive of multiculturalism as an ideology, but rather neutral in their support for multicultural policy. Indeed, multicultural policy was, again, supported significantly less 
strongly than multicultural ideology, $t(201)=-5.32, p<.001, d=0.75$. Interestingly, the two facets of multiculturalism were not correlated in this study $(r=.06, p=.387)$. However, a stronger belief in individual responsibility was associated with decreased support for multicultural policy $(r=-.14, p=.046)$, but not ideology $(r=.00, p=.956)$, consistent with Study 1 .

Hypothesis testing. Table 1 shows hierarchical regression results assessing the impact of conditions, individual responsibility belief, and interactions on support for multicultural policy and ideology. Step 1 displays main effects. No differences were found between experimental conditions on support for either facet of multiculturalism, although a stronger belief in individual responsibility was associated with (just) significantly less support for multicultural policy, 95\% CI [-0.35, -0.00], $p=.046, d=0.29$, consistent with Study 1 . Step 2 incorporated the interactions between experimental conditions and individual responsibility belief, testing our two main hypotheses. As expected, results were consistent with those found in Study 1, albeit pertaining to distinct groups. When predicting support for multicultural policy, the expected interaction between status and individual responsibility was (just) significant (H1), 95\% CI [-0.35, -0.01], $p=.043, d=0.29$. When predicting support for multicultural ideology, the expected interaction between origin and individual responsibility was significant (H2), 95\% CI [-0.40, -0.10], $p=.001, d=0.48$. Figure 2 shows the decompositions of these interaction effects, including unstandardized coefficients (and standard errors) of simple effects.

Simple effects for the significant interaction term on support for multicultural policy showed that for high status group members, a stronger belief in individual responsibility was associated with weaker support for multicultural policy, 95\% CI [-0.61, -0.11], $t(194)=-2.83$, $p=.005, d=0.41$, consistent with H1. For low status group members, support for multicultural policy remained on the same level regardless of individual responsibility belief, 
$95 \%$ CI $[-0.24,0.24], t(194)=-0.02, p=.981$ (other simple effect descriptions in supplementary materials). Low status group members therefore generally perceived less incompatibility between individual responsibility and multiculturalism policy than high status group members (see Figure 2).

Table 1

Hierarchical regression results: Effects of conditions, individual responsibility belief and interactions on support for Multicultural (MC) policy and ideology (Study 2)

MC Policy

B $\quad S E$

MC Ideology

$B \quad S E \quad t$

Step 1

Status: Low/High

$\begin{array}{lll}-0.12 & 0.07 \quad-1.61\end{array}$

$-0.10 \quad 0.06$

$-1.62$

Origin: Immigrant/Native

$-0.03 \quad 0.07$

$-0.39$

$0.05 \quad 0.06$

0.70

Size: Minority/Majority

$0.08 \quad 0.07$

1.13

$0.06 \quad 0.06$

0.88

Individual Responsibility

$\begin{array}{lll}-0.18 & 0.09 & -2.01 *\end{array}$

$0.01 \quad 0.08$

0.09

(IndResp)

Step 2

\begin{tabular}{|c|c|c|c|c|c|c|}
\hline Status*IndResp & -0.18 & 0.09 & $-2.03 *$ & 0.02 & 0.08 & 0.31 \\
\hline Origin*IndResp & -0.08 & 0.09 & -0.89 & -0.25 & 0.08 & $-3.34 * *$ \\
\hline Size*IndResp & 0.03 & 0.09 & 0.33 & 0.13 & 0.08 & 1.67 \\
\hline step 1 & \multicolumn{3}{|l|}{.04} & \multicolumn{3}{|l|}{.02} \\
\hline$R^{2}$ & \multicolumn{3}{|l|}{.02} & \multicolumn{3}{|l|}{$.06^{* *}$} \\
\hline statistic $_{\text {final model }}$ & \multicolumn{3}{|c|}{$1.88(d f=7,194)$} & \multicolumn{3}{|c|}{$2.43^{*}(d f=7,194)$} \\
\hline
\end{tabular}

Note. ${ }^{* *} p<.01,{ }^{*} p<.05$

Conditions coded so that -1 represents low status, immigrant and minority groups; 1 represents high status, native and majority groups. IndResp mean centred. 

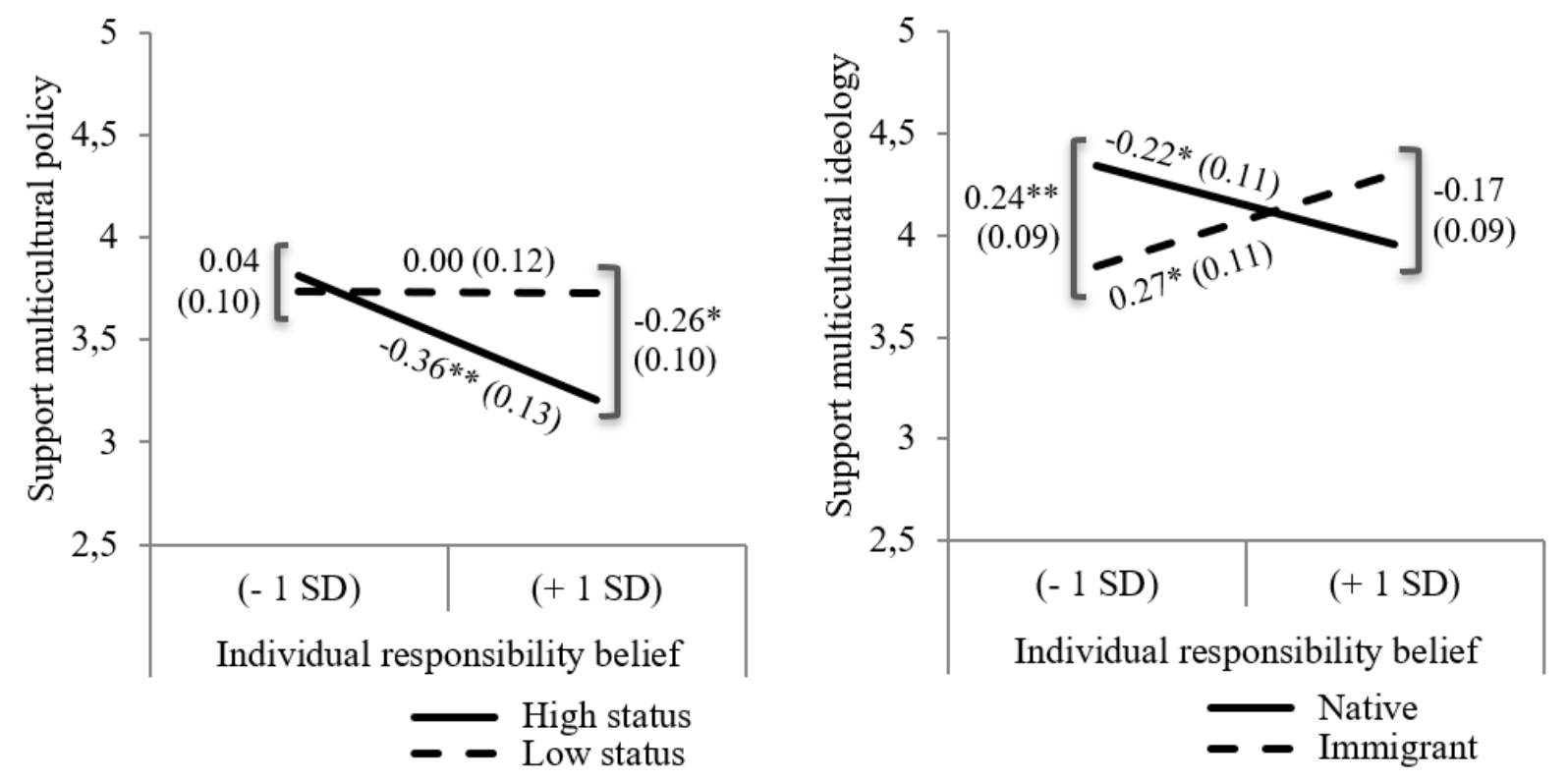

Figure 2. Perceived (in)compatibility between individual responsibility and multiculturalism by experimental conditions (Study 2). Numbers represent unstandardized coefficients (and standard errors) of simple effects/slopes. $* * p<.01, * p<.05$.

In order to explore whether this interaction between status and individual responsibility was more relevant for natives or for immigrants, a supplementary regression model was tested incorporating a three-way interaction between individual responsibility, origin and status. In this model, the numerical size of the group was simply controlled for. Results revealed a non-significant, albeit marginal, three-way interaction, $B=-0.15,95 \% \mathrm{CI}$ $[-0.32,0.02], S E=0.09, t(193)=-1.71, p=.089, d=0.25$, suggesting that status and individual responsibility interacted for natives, $B=-0.32,95 \%$ CI $[-0.56,-0.08], S E=0.12$, $t(193)=-2.64 p=.009, d=0.38$, but not for immigrants, $B=-0.03,95 \%$ CI $[-0.27,0.21], S E$ $=0.12, t(193)=-0.22 p=.825$. Indeed, high status natives perceived incompatibility between individual responsibility and multiculturalism, $B=-0.60,95 \% \mathrm{CI}[-0.95,-0.25], S E=0.18$, $t(193)=-3.39, p<.001, d=0.49$, while low status natives did not, $B=0.05,95 \%$ CI [-0.29, 0.38], $S E=0.17, t(193)=0.27, p=.789$ (nor did high or low status immigrants, $p=.438, p=$ .619 , respectively). 
Simple effects for the significant interaction term on support for multicultural ideology (see Figure 2) showed that for natives, a stronger belief in individual responsibility was associated with significantly less support for multicultural ideology, 95\% CI [-0.44, -0.02], $t(194)=-2.16, p=.032, d=0.31$, consistent with H2a. For immigrants, a stronger belief in individual responsibility was associated with significantly more support for multicultural ideology, 95\% CI [0.06, 0.48], $t(194)=2.56, p=.011, d=0.37$, consistent with H2b. Participants in the experimental native group therefore perceived incompatibility between individual responsibility and multiculturalism ideology, while those in the experimental immigrant group perceived compatibility between the two.

\section{Discussion}

Results from this second study both corroborate and extend those from Study 1. Members of an experimental high status group perceived significantly less compatibility between individual responsibility and multicultural policy than members of the low status group (H1). Members of an experimental immigrant group perceived relative compatibility between multicultural ideology and individual responsibility, while members of the native group perceived them as relatively incompatible $(\mathrm{H} 2)$.

This study has limitations. While the results were relatively consistent with those obtained in Study 1, the power of the study remained rather weak, with slightly fewer participants than anticipated to replicate both interactions from Study 1. Moreover, internal consistency of the three major measures was lower compared to those in Study 1, and the correlation between the two facets of multiculturalism was no longer significant. These outcomes may be due to participants' struggle to answer questions as members of fictitious experimental groups, especially when one's assigned position differs from one's actual position in society. 
Another limitation common to both Studies 1 and 2 was the use of a descriptive measure of individual responsibility, gauging the extent to which individuals believe society is currently functioning according to individual justice principles. Since classical liberalism as a political theory involves a normative perspective concerning how individuals and societies ought to function, Study 3 tested the same hypotheses with newly developed, prescriptive measures of classical liberalism.

\section{Study 3}

Study 3 served as a replication of Study 2, involving a similar description of a fictitious society. This time, to simplify the paradigm, only status and origin were manipulated orthogonally, and new measures of classical liberalism were included.

The same two hypotheses from Study 2 were maintained and adapted accordingly. Firstly, only high status group members (in particular high status natives) should perceive incompatibility between multicultural policy and individual responsibility (H1), while low status group members should not. Secondly, native group members should perceive incompatibility between multicultural ideology and individual responsibility $(\mathrm{H} 2 \mathrm{a})$, while immigrant group members should perceive compatibility between them $(\mathrm{H} 2 \mathrm{~b})$.

\section{Method}

Participants. Participants included 164 students in an introductory social psychology course at a university in French-speaking Switzerland. This sample size was determined before any data analysis. ${ }^{9}$ Age ranged from 18 to $46(M=20.94, S D=2.89 ; 2$ non-response $)$, with $98 \%$ under 27 years old. Participants were predominantly women $(81 \%, N=133 ; 2$ nonresponse) and $52 \%$ were solely Swiss $(N=86)$. The remainder were Swiss with dual (or triple) nationality $(28 \% ; N=46)$ or non-Swiss $(15 \%, N=25 ; 2$ non-response).

\footnotetext{
${ }^{9}$ While we were hoping for a larger sample (at least $N=200$ ), this was the number of students in the class who agreed to participate in the study.
} 
Procedure and materials. During class, participants filled out a questionnaire similar to the one used in Study 2, with the following changes.

Prescriptive belief in individual responsibility. First, participants responded to a fouritem measure of prescriptive individual responsibility that was constructed and validated in a pilot study. ${ }^{10}$ Only the following three items were retained because of their greater coherence and improved internal consistency: "Individuals should be responsible for their progress/actions/own outcomes" ( $\alpha=.75$ instead of $\alpha=.69, M=4.44, S D=1.01$; removed item: "Switzerland is a society where all individuals should try to obtain a better position in society"). ${ }^{11}$ The pilot study $(N=65)$ showed significant correlations with other indicators of classical liberalism such as free-market ideology $(r=.41, p=.001)$, individual human right to property $(r=.36, p=.004)$, and the previously used measure of (descriptive) belief in individual responsibility $(r=.55, p<.001)$.

Experimental design. Each participant was randomly assigned to one of four conditions, according to a $2 \times 2$ experimental design. The exact same scenario as in Study 2 was presented to them, except that only status (high, $\mathrm{N}=82$, versus low, $\mathrm{N}=82$ ) and origin (immigrant, $\mathrm{N}=81$, versus native, $\mathrm{N}=83$ ) were manipulated.

Support for multicultural policy and ideology. As in Study 2, at the end of the scenario, participants as members of their assigned groups were asked to respond to a survey regarding their opinion towards multicultural policy (three items; $\alpha=.62, M=3.84, S D=$ 0.96 ) and ideology (four items; $\alpha=.67, M=4.46, S D=0.79) .{ }^{12}$

\footnotetext{
${ }^{10}$ Participants also responded to a newly constructed more abstract measure of classical liberalism (six items, $\alpha=$ .68). The measure is described, and results are reported, in supplementary materials.

${ }^{11}$ The item-total correlations were all satisfactory for the 3-item measure (ranging from $r=.52$ to $r=.68$ ) but were not for the 4-item measure ( $r=.27$ for the excluded item; Nunnally \& Bernstein (1994) suggest $r=.30$ is a conservative cut-off for item-total correlations). In the pilot study, the 4 -item measure had better internal consistency ( $\alpha=.82 ; \alpha=.84$ for the 3-item measure); Results using this 4-item measure are reported in supplementary materials.

12 The same distractors as those in Studies 1 and 2 were included in Study 3.
} 
Manipulation checks. Participants responded to the same manipulation checks from Study 2, composed of perceived privilege $(\alpha=.74)$, recall and understanding of their high/low $(r=-.85, p<.001)$ and native/immigrant $(r=-.83, p<.001)$ status, and easiness/difficulty of the exercise (two items treated separately, $r=-.08, p=.209$ )

\section{Results}

Manipulations were checked first, followed by descriptive statistics and hypothesis testing. Maximum Likelihood (ML) estimation method was applied for missing cases of all items (0.56\% missing data) except sociodemographic ones and all analyses were also performed controlling for citizenship, gender and age (see supplementary materials).

\section{Manipulation checks.}

Perceived privilege. In a two-way ANOVA, tests of between-subjects effects showed that participants assigned to the high status group $(M=4.74, S E=0.09)$ felt significantly more privileged than those assigned to the low status group $(M=3.36, S E=0.09), F(1,160)$ $=114.18, p<.001, \eta_{\mathrm{p}}{ }^{2}=0.42$, and natives $(M=4.25, S E=0.09)$ felt significantly more privileged than immigrants $(M=3.85, S E=0.09), F(1,160)=9.72, p=.002, \eta_{\mathrm{p}}{ }^{2}=0.06$.

Recall and understanding of the text. A two-way MANOVA showed that low status group members $(M=2.03, S E=0.11)$ recognized their lower status in comparison to high status group members $(M=4.86, S E=0.11), F(1,160)=331.40, p<.001, \eta_{\mathrm{p}}{ }^{2}=0.67$. Immigrants $(M=1.82, S E=0.12)$ recognized their immigrant status in comparison to natives $(M=5.21, S E=0.12), F(1,160)=384.15, p<.001, \eta_{\mathrm{p}}^{2}=0.71$.

Difficulty of the exercise. A three-way MANOVA predicting the two measures of perceived easiness and difficulty of the task showed that high status group members $(M=$ $3.81, S E=0.15)$ experienced greater difficulty to imagine themselves as a member of their group in comparison to low status group members $(M=3.16, S E=0.15), F(1,160)=9.26, p$ $=.003, \eta_{\mathrm{p}}^{2}=0.06$. No other main or interaction effects were found. 
Descriptive statistics and correlations. The means presented in the methods section for the overall sample show that participants generally agreed with the idea that all individuals should be responsible for progress. They were also fairly supportive of multiculturalism as an ideology, but again rather neutral in their support for multicultural policy which was supported less, $t(163)=-7.52, p<.001, d=1.18$. As in Study 1 , the two facets of multiculturalism were positively correlated $(r=.30, p<.001)$, and the prescriptive individual responsibility belief was neither significantly associated with multicultural policy $(r=-.04, p$ $=.608)$ nor ideology $(r=-.01, p=.863)$.

Hypothesis testing. Table 2 shows hierarchical regression results assessing the impact of conditions, (prescriptive) individual responsibility belief, and interactions on support for multicultural policy and ideology.

Step 1 displays main effects. No differences were found between experimental conditions on support for either facet of multiculturalism and the prescriptive belief in individual responsibility remained non-significant. Step 2 incorporated the interactions between experimental conditions and individual responsibility belief, testing our two main hypotheses. When predicting support for multicultural policy, the two-way interaction between status and individual responsibility was non-significant. ${ }^{13}$ However, the three-way interaction in step 3 was significant, 95\% CI [-0.30, -0.01], $p=.034, d=0.34$, showing that

\footnotetext{
${ }^{13}$ A random-effects meta-analysis (Cumming, 2014; Świątkowski \& Dompnier, 2017) using R (Viechtbauer, 2010) was conducted on reported results from all three studies testing the two-way interaction effect predicting support for multicultural policy (interaction between status in Studies 2 and 3, citizenship in Study 1, and individual responsibility). The interaction was significant, $B=-0.16,95 \% \mathrm{CI}[-0.25,-0.06], S E=0.05, Z=-3.07$, $p=.002$ and the test for heterogeneity was non-significant, $Q(2)=1.57, p=.456$. To verify robustness, because the models differed in complexity across studies, a simpler, identical model to Study 1 was also calculated for Studies 2 and 3 (including only two main effects and the two-way interaction between status and individual responsibility as predictors) and was used to conduct an additional meta-analysis on the two-way interaction effect from all three studies; Interpretation of results was identical. A meta-analysis was then conducted on reported simple effects decomposing the two-way interaction from all three studies. As expected, for (Swiss) high status group members, the belief in individual responsibility was associated with significantly less support for multicultural policy, $B=0.40,95 \%$ CI $[-0.75,-0.05], S E=0.18, Z=-2.26, p=.024$ (heterogeneity was significant, $Q(2)=15.03, p<.001$, justifying the distinction between natives and immigrants in the ultimate three-way interaction). For low status group members, support for multicultural policy remained on a similar level regardless of individual responsibility belief, $B=-0.01,95 \%$ CI $[-0.15,0.14], S E=0.07, Z=-0.11, p=$ .916 (heterogeneity was non-significant, $Q(2)=1.20, p=.550$ ).
} 
this interaction occurred only for natives (H1), $B=-0.28,95 \%$ CI $[-0.49,-0.06], S E=0.11$, $t(156)=-2.54 p=.012, d=0.41$, and not for immigrants, $B=0.03,95 \%$ CI $[-0.15,0.22], S E$ $=0.09, t(156)=0.34 p=.735$, consistent with Study 2 .

Table 2

Hierarchical regression results: Effects of conditions, prescriptive individual responsibility belief and interactions on support for Multicultural (MC) policy and ideology (Study 3)

\begin{tabular}{|c|c|c|c|c|c|c|}
\hline & \multicolumn{3}{|c|}{ MC Policy } & \multicolumn{3}{|c|}{ MC Ideology } \\
\hline & $B$ & $S E$ & $t$ & $B$ & $S E$ & $t$ \\
\hline \multicolumn{7}{|l|}{ Step 1} \\
\hline Status: Low/High & 0.13 & 0.08 & 1.78 & -0.02 & 0.06 & -0.37 \\
\hline Origin: Immigrant/Native & -0.06 & 0.08 & -0.81 & -0.01 & 0.06 & -0.08 \\
\hline Prescriptive Individual & -0.04 & 0.07 & -0.56 & -0.01 & 0.06 & -0.16 \\
\hline \multicolumn{7}{|l|}{ Responsibility (PIndResp) } \\
\hline \multicolumn{7}{|l|}{ Step 2} \\
\hline Status*PIndResp & -0.09 & 0.08 & -1.21 & 0.07 & 0.06 & 1.07 \\
\hline Origin*PIndResp & 0.01 & 0.08 & 0.16 & -0.13 & 0.06 & $-2.03 *$ \\
\hline \multicolumn{7}{|l|}{ Step 3} \\
\hline Status*Origin & 0.26 & 0.07 & $3.58 * * *$ & 0.11 & 0.06 & 1.74 \\
\hline Status*Origin*PIndResp & -0.16 & 0.07 & $-2.14 *$ & -0.08 & 0.06 & -1.22 \\
\hline$R_{\text {step } 1}^{2}$ & \multicolumn{3}{|l|}{.03} & \multicolumn{3}{|l|}{.00} \\
\hline$\Delta R_{\text {step } 2}^{2}$ & \multicolumn{3}{|l|}{.01} & \multicolumn{3}{|l|}{.03} \\
\hline$\Delta R_{\text {step } 3}^{2}$ & \multicolumn{6}{|l|}{$.10 * * *$} \\
\hline$F$ statistic final model & \multicolumn{3}{|c|}{$3.36^{* *}(d f=7,156)$} & \multicolumn{3}{|c|}{$1.15(d f=5,158)$} \\
\hline
\end{tabular}

Conditions coded so that -1 represents low status and immigrant groups; 1 represents high status and native groups. PIndResp mean centred. 
When predicting support for multicultural ideology, the expected interaction between origin and individual responsibility was (just) significant (H2), 95\% CI [-0.25, -0.00], $p=$ $.044, d=0.32$. While step 3 for the model predicting support for multicultural ideology is shown in Table 2 for reasons of symmetry, we neither expected nor found a significant threeway interaction incorporating the status manipulation.

Figure 3 shows the decomposition of the significant three-way interaction term on support for multicultural policy. Simple effects showed that among immigrants, both low status and high status group members' support for multicultural policy remained on a similar level regardless of prescriptive individual responsibility belief, 95\% CI [-0.37, 0.18], $t(156)=$ $-0.70, p=.486 ; 95 \%$ CI $[-0.29,0.22], t(156)=-0.26, p=.797$, respectively. Among low status natives, support for multicultural policy also remained on a similar level regardless of individual responsibility belief, 95\% CI [-0.09, 0.50], $t(156)=1.40, p=.163$. However, among high status natives, a stronger belief in individual responsibility was associated with significantly weaker support for multicultural policy, 95\% CI [-0.66, -0.03], $t(156)=-2.17, p$ $=.032, d=0.35$, consistent with $\mathrm{H} 1$ (other simple effect descriptions in supplementary materials). Immigrants and low status natives therefore generally perceived less incompatibility between individual responsibility and multicultural policy than high status natives. 


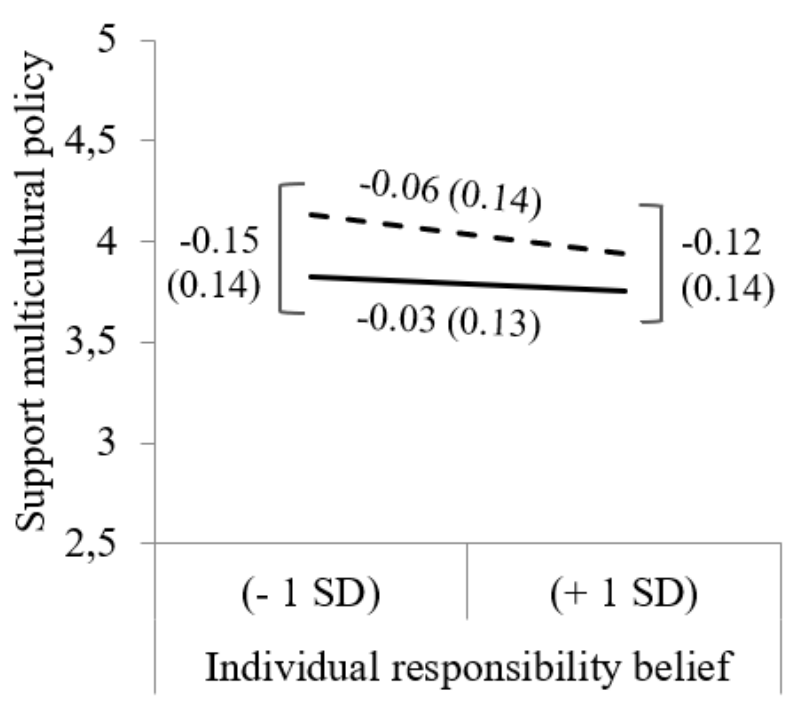

Immigrant

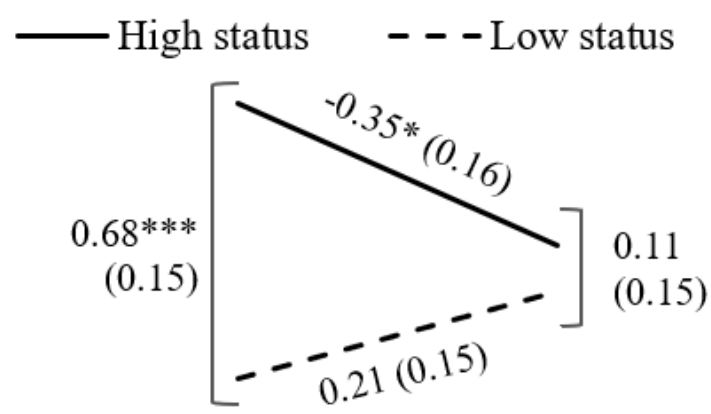

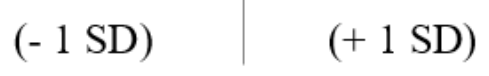

Individual responsibility belief

Native

Figure 3. Perceived (in)compatibility between prescriptive individual responsibility and multicultural policy by experimental conditions (Study 3). Numbers represent unstandardized coefficients (and standard errors) of simple effects/slopes.

$* * * p<.001, * p<.05$.

Simple effects for the significant interaction term on support for multicultural ideology were all non-significant but in the expected direction. For natives, the belief in individual responsibility was not associated with support for multicultural ideology, although the sign was indeed negative (H2a), $B=-0.16,95 \% \mathrm{CI}[-0.34,0.03], S E=0.09, t(158)=-1.66, p=$ $.100, d=0.26$. For immigrants, the belief in individual responsibility was not associated with support for multicultural ideology either, although the sign was indeed positive $(\mathrm{H} 2 \mathrm{~b}), B=$ $0.10,95 \%$ CI $[-0.06,0.26], S E=0.08, t(156)=1.19, p=.236, d=0.24$. These non-significant simple effects are reported to aid in interpreting the interaction term which showed that participants in the experimental native and immigrant groups differed from each other, in the expected direction, in the degree to which they perceived (in)compatibility between prescriptive individual responsibility and multicultural ideology. ${ }^{14}$

\footnotetext{
${ }^{14}$ A random-effects meta-analysis was conducted on reported results from all three studies testing this two-way interaction effect predicting support for multicultural ideology. The interaction was significant, $B=-0.23,95 \%$ CI $[-0.35,-0.10], S E=0.06, Z=-3.62, p<.001$ and the test for heterogeneity was non-significant, $Q(2)=4.17, p$ $=.124$. To verify robustness, because the models differed in complexity across studies, a simpler, identical model to Study 1 was also calculated for Studies 2 and 3 (including only two main effects and the two-way
} 


\section{Discussion}

Results from this third study provide additional support for the conjecture that membership in (culturally and economically) subordinate groups increases perceived compatibility between liberalism and multiculturalism. Indeed, compatibility between (prescriptive) individual responsibility and multicultural policy was contingent predominantly on one's experimental social status, whereby high status natives perceived significantly greater incompatibility than low status natives (H1). Immigrants, regardless of their status, did not perceive incompatibility.

Compatibility between individual responsibility and multicultural ideology, in turn, depended on the experimental origin of participants $(\mathrm{H} 2)$. We were able to replicate this interaction from Study 2 using an alternative, prescriptive measure of belief in individual responsibility. While simple effects were non-significant in the present study, an internal meta-analysis attested to the robustness of these effects suggesting that natives perceive incompatibility between individual responsibility and multicultural ideology, while immigrants perceive compatibility between the two. Consistent with the argument that individual and collective forms of justice are more compatible for members of this immigrant group, one participant wrote, "as a member of my [experimental immigrant] group, I would like to conserve my values, that shouldn't be erased, but accepted. I would also like to have the same chances as the others, even if this implies 'blending into the masses"”.

It is worth noting that in the present study, it seemed as though high status group members were more supportive of multicultural policy than low status group members, which could appear counterintuitive and opposite to findings from Study 2. However, this

\footnotetext{
interaction between origin and individual responsibility as predictors) and was used to conduct an additional meta-analysis on the interaction effect from all three studies; Interpretation of results was identical. A metaanalysis was then conducted on reported simple effects decomposing the interaction from all three studies. For (Swiss) natives, the belief in individual responsibility was associated with significantly less support for multicultural ideology (H2a), $B=0.24,95 \%$ CI $[-0.36,-0.12], S E=0.06, Z=-4.01, p<.001$ (heterogeneity was non-significant, $Q(2)=2.03, p=.362$ ), and for immigrants, the belief in individual responsibility was associated with significantly more support for multicultural ideology $(\mathrm{H} 2 \mathrm{~b}), B=0.20,95 \% \mathrm{CI}[0.05,0.35], S E=0.07, Z=$ $2.69, p=.007$ (heterogeneity was non-significant, $Q(2)=2.66, p=.264$ ).
} 
directionality was driven by the native condition at low levels of the belief in individual responsibility. Perhaps low status natives were particularly opposed to multicultural policies because they perceived benefits to disadvantaged outgroups (i.e., immigrants), reinforcing their own disadvantage. High status natives, conversely, may have felt they were in a comfortable position where they could look out for the disadvantaged, as exemplified by a participant's comment: "Each individual should have the same living conditions; if equity is not possible as it stands then [as an experimental high status native], it seems obvious to me to use affirmative action.” This quote is also interesting as it shows how support for multicultural policy (affirmative action) implies a distancing from individual justice principles (equity) for high status natives, in line with our basic claim that high status natives perceive incompatibility between individual responsibility and multicultural policy, while low status natives do not.

\section{General discussion}

The three studies presented in this paper support the general hypothesis according to which members of dominant and subordinate groups differ in the degree to which they perceive multiculturalism (collective justice) and classical liberalism (individual justice) as (in)compatible. Indeed, across all studies, the magnitude or direction of the relationship between (descriptive and prescriptive) individual responsibility and multiculturalism was found to differ between (high status) natives and immigrants or other subordinate groups; a finding which was also supported by meta-analyses. While the relationship between individual responsibility and multiculturalism itself was not always significant, immigrants and other subordinate group members consistently perceived comparatively weaker incompatibility between liberalism and multiculturalism than native, dominant group members. More specifically, Study 1 provided preliminary evidence that actual cultural minorities perceived greater compatibility compared to native majorities. Studies 2 and 3 
confirmed and extended this finding by experimentally differentiating the core criteria associated with membership in cultural minority versus native majority groups, that is, social status and cultural origin (and size, Study 2).

A key feature of these studies was the simultaneous inclusion of two facets of multiculturalism: ideology and policy. While both are based on collective justice principles, ideology taps the abstract and general principles of multiculturalism by emphasizing groupbased cultural recognition. Policy, in turn, assesses the implementation of multicultural principles. It is therefore more concrete than ideology, highlighting the socio-economic component of multiculturalism associated not only with recognition, but also with groupbased compensation of inequality. Overall, policy was less strongly supported than ideology, with remarkably strong effects across the three studies and consistent with our expectations (see Sears et al., 1999; Yogeeswaran \& Dasgupta, 2014). However, the overall pattern of results for both facets of multiculturalism was consistent with the asymmetric compatibility hypothesis.

Existing intergroup research has shown that immigrants and other culturally subordinate groups support multiculturalism to a greater extent than natives (Arends-Tóth \& Van de Vijver, 2003; Ryan et al., 2007; Verkuyten, 2005, 2006; Wolsko et al., 2006). Our studies show, however, that this is not always the case. Studies 1 and 2 suggest, for example, that the difference may occur only when the descriptive belief in individual responsibility is strong, that is, when dominant norms of individual justice are salient. In other words, natives are particularly likely to oppose multiculturalism when they see the society as a space of individual competition, but less so when they question the primacy of individual justice principles.

These findings further suggest that the meaning of individual justice and responsibility is not the same for dominant and subordinate groups. For dominant groups, classical liberal 
norms of individual justice — in particular the belief in individual responsibility — are known to be "system-justifying” (see Bobocel et al., 1998; McCoy \& Major, 2007), legitimizing social inequalities (Major et al., 2002; Sidanius \& Pratto, 1999). (High status) natives may show opposition to multiculturalism when they endorse these legitimizing norms in order to reinforce their dominant position and to oppose social change (see also Zárate, Shaw, Marquez, \& Biagas, 2012). Conversely, when members of these dominant groups are aware of inequalities (which is explicit in Study 2), they may acknowledge their group-based privileges and more readily support inequality-reducing policies (see Leach et al., 2006; Powell et al., 2005; see also Moscovici \& Pérez, 2007). Nevertheless, it is also plausible that dominant group members support pro-minority policies to preserve inequalities, appeasing subordinate group members' concerns for equality and preventing them from engaging in collective action (Chow, Lowery, \& Hogan, 2013). Despite the possibility of these alternative motivations, the take-home message is that for high status and native group members, a just society can be based on either individual or collective justice principles as they struggle to reconcile both by supporting them simultaneously.

For group members who are lower in the social hierarchy, however, classical liberal beliefs of individual responsibility may have a different meaning. Our findings show that unlike for (high status) natives, attitudes of immigrants and low status natives towards inequality-reducing multicultural policies do not depend on beliefs in individual responsibility. Moreover, immigrant attitudes towards multicultural ideology became more positive when beliefs in individual responsibility were high (vs. low; supported by a metaanalysis of simple effects). Indeed, subordinate group members, whether they be immigrants or low status natives, are acutely aware of the dominance of individual justice principles in society (Deschamps. 1982; Sampson, 1988). However, their subordinate position leads them 
to consider that their successful integration in society requires endorsement of both individual and collective justice principles (see Simon, 2011; Simon \& Ruhs, 2008).

Another reason natives and high status groups show opposition to multiculturalism is because they feel both their national identity and their dominant material status may be threatened by multicultural ideology and/or policy (Badea, Iyer, \& Aebischer, 2018; Mahfud, Badea, Verkuyten, \& Reynolds, 2017; Morrison, Plaut, \& Ybarra, 2010; Plaut, Thomas, Hurd, \& Romano, 2018; Yogeeswaran \& Dasgupta, 2014). One could argue that weak support for multicultural ideology and policy in our studies results from perceived symbolic and material threat, respectively. From this point of view, our results suggest that natives, in general, are more (symbolically) threatened by multicultural ideology and the recognition of cultural differences when dominant norms of individual justice are salient. They also suggest that high status natives, in particular, are more (materially) threatened by multicultural policy and the reduction of inequality when these same dominant norms are salient. Two important implications stem from this interpretation: that the type of perceived threat is determined by the kind of (asymmetric) group one belongs to, and, more generally, that among dominant group members, threat perceptions are anchored in their normative concern for individual justice.

\section{Remaining Questions and Limitations}

Some of our findings were more peripheral and less consistent across studies. These include (1) the non-significant correlation between multicultural ideology and policy in Study 2, (2) the significant simple effect in Study 2 suggesting immigrants are less supportive of multicultural ideology than natives when they are aware of structural inequalities, and (3) the significant simple effect in Study 3 suggesting low status natives are significantly less supportive of multicultural policy than high status natives when they have a low level of the prescriptive belief in individual responsibility. 
The first finding provides supplementary support that the ideology and policy facets of multiculturalism should be treated separately as they seem to be rather orthogonal to each other (and thus perhaps not so "unidimensional" as previously suggested), despite the fact that both are based on collective justice principles. The second finding (immigrants became more opposed to multicultural ideology in comparison to natives when the descriptive belief in individual responsibility was low) provides support for the conjecture that immigrant endorsement of multicultural ideology is conditional: In a society where some groups face greater obstacles to progress than others, immigrants may be concerned that inequalities are legitimized and essentialised through the formal recognition of cultural differences. Indeed, minorities consistently demonstrated support for cultural recognition especially when they believed individuals are and should be individually responsible, autonomous and free, suggesting that members of culturally subordinate groups require multiculturalism and liberalism to coexist to feel they live in a just society. The third finding is reminiscent of national chauvinism (Meuleman, Bekhuis, Lubbers, \& Scheepers, 2013) and rising right-wing populism (Staerklé \& Green, 2018) among low status natives, who may be particularly wary of cultural minority group compensation when they, themselves, feel victimised and unrecognized as long-standing members of society. These findings should, however, be interpreted with caution given their inconsistency paired with the low power of our studies and the hypothetical nature of our scenarios.

The experimental simulation procedure used in Studies 2 and 3 has its own limitations. Researchers acknowledge that being randomly assigned to an experimental group in a fictitious society does not fully simulate what it really means to be a member of such a group (see Azzi, 1992; Jetten et al., 2015). Moreover, our complex experimental design may have left some participants struggling to remember and interpret their group membership. Taking on the role of a low status, native, numerical minority group member in Study 2, for example, 
may have had little intuitive meaning for participants living in Switzerland, given that it is not a settler country. The simpler orthogonal design adopted in Study 3 did compensate for some of the added complexity in Study 2.

Nevertheless, this experimental design also had its strengths. First, the design allowed us to disentangle multiple asymmetric group criteria in a controlled manner. This would have been difficult (if not impossible) using real groups. Second, the experimental method was complementary to the convenience sample and correlational approach used in Study 1, allowing us to uncover relatively consistent findings in line with our general hypothesis. Third, the scenario of a fictitious society made the immigrant vs. native conditions conceivable; a manipulation that would have been more difficult to implement with traditional, minimal experimental groups (see Sachdev \& Bourhis, 1991; Simon et al., 2001). To our knowledge, this immigrant vs. native manipulation has never been used before. Hence, we hope our approach may offer some guidance for future research on attitudes towards multiculturalism.

\section{Conclusion}

The results of our studies are relevant to consider in the context of current European cultural diversity management policies. In recent years, European countries have increasingly implemented civic integration policies (Joppke, 2017; Lesinska, 2014). The goal of these policies is to facilitate successful integration of immigrants and ethnic minorities into common life through development of dominant language and work-related skills, for example. However, these policies tend to focus on individual rights and responsibilities, placing little emphasis on cultural recognition, affirmative action, and group-based inequality. Multiculturalism, depending on its implementation, seeks to ensure the individual liberty of all people, including those that may be disadvantaged by society's existing laws, regulations and norms that are often - though not necessarily intentionally - more favourable for the 
dominant group (Gale \& Staerklé, 2017; Kymlicka, 1995, 2001). Our results suggest that the coexistence of classical liberalism and multiculturalism creates a sense of justice that is particularly important for members of low status, subordinate groups. Future research should explore the specific social and psychological conditions underlying this perceived compatibility, including political and normative contexts as well as different levels of national and ethnic identity of (various religious, cultural, linguistic, socio-economic and national) group members. 


\section{Open Practices}

The data and material associated with the studies in this article are available at https://data.mendeley.com/datasets/f2wvbpsmyv/draft?a=e8c3968c-8b4a-47b5-a7d1$\underline{5 \mathrm{aa} 120 \mathrm{f} 1 \mathrm{bc} 76}$ 


\section{References}

Antonini, M. G. (2017, December 1). Re: What's on your mind? [Post on personal facebook profile]. Retrieved from https://www.facebook.com/matteo.g.antonini

Arends-Tóth, J., \& Van de Vijver, F. J. R. (2003). Multiculturalism and acculturation: Views of Dutch and Turkish-Dutch. European Journal of Social Psychology, 33, 249-266. http://doi.org/10.1002/ejsp.143

Azzi, A. E. (1992). Procedural justice and the allocation of power in intergroup relations: Studies in the United States and South Africa. Personality and Social Psychology Bulletin, 18, 736-747. http://doi.org/10.1177/0146167292186010

Azzi, A. E. (1998). From competitive interests, perceived injustice, and identity needs to collective action: Psychological mechanisms in ethnic nationalism. In C. Dandeker (Ed.), Nationalism and violence (pp. 73-138). New Brunswick, NJ: Transaction Press.

Badea, C., Iyer, A., \& Aebischer, V. (2018). National identification, endorsement of acculturation ideologies and prejudice: The impact of the perceived threat of immigration. International Review of Social Psychology, 31, 1-10. http://doi.org/10.5334/irsp.147

Barry, B. (2001). Culture and equality: An egalitarian critique of multiculturalism. Cambridge, MA: Harvard.

Berry, J. W., \& Kalin, R. (1995). Multicultural and ethnic attitudes in Canada: An overview of the 1991 national survey. Canadian Journal of Behavioural Science, 27, 301-320. http://doi.org/doi:10.1037/0008-400X.27.3.301

Bobocel, D. R., Son Hing, L. S., Davey, L. M., Stanley, D. J., \& Zanna, M. P. (1998). Justicebased opposition to social policies: Is it genuine? Journal of Personality and Social Psychology, 75, 653-669.

Bourdieu, P. (1979). La distinction: Critique sociale du jugement. Paris: Minuit. 
Brewer, M. B. (1991). The social self: On being the same and different at the same time. Personality and Social Psychology Bulletin, 17, 475-482.

Brewer, M. B. (1997). The social psychology of intergroup relations: Can research inform practice? Journal of Social Issues, 53, 197-211.

Brickman, P., Folger, R., Goode, E., \& Schul, Y. (1981). Microjustice and macrojustice. In M. J. Lerner \& S. C. Lerner (Eds.), The justice motive in social behavior: Adapting to times of scarcity and change (pp. 173-202). New York: Plenum Press.

Bruckmüller, S., \& Abele, A. E. (2010). Comparison focus in intergroup comparisons: Who we compare to whom influences who we see as powerful and agentic. Personality and Social Psychology Bulletin, 36, 1424-1435. http://doi.org/10.1177/0146167210383581

Chow, R. M., Lowery, B. S., \& Hogan, C. M. (2013). Appeasement: Whites' strategic support for affirmative action. Personality and Social Psychology Bulletin, 39, 332-345. http://doi.org/10.1177/0146167212475224

Conway, M., Pizzamiglio, M. T., \& Mount, L. (1996). Status, communality, and agency: Implications for stereotypes of gender and other groups. Journal of Personality and Social Psychology, 71, 25-38. http://doi.org/10.1037/0022-3514.71.1.25

Cumming, G. (2014). The new statistics: Why and how. Psychological Science, 25, 7-29. http://doi.org/https://doi.org/10.1177/0956797613504966

Dandy, J., \& Pe-Pua, R. (2010). Attitudes to multiculturalism, immigration and cultural diversity: Comparison of dominant and non-dominant groups in three Australian states. International Journal of Intercultural Relations, 34, 34-46. http://doi.org/10.1016/j.ijintrel.2009.10.003

Deschamps, J.-C. (1982). Social identity and relations of power between groups. In H. Tajfel (Ed.), Social identity and intergroup relations (pp. 85-98). Cambridge, UK: Cambridge University Press. 
Gale, J., \& Staerklé, C. (2017). Multiculturalisme et justice sociale. In C. Staerklé \& F. Butera (Eds.), Conflits constructifs, conflits destructifs : Regards psychosociaux (pp. 205-220). Lausanne, Suisse: Editions Antipodes.

Green, E. G. T., \& Staerklé, C. (2013). Migration and multiculturalism. In L. Huddy, D. O. Sears, \& J. S. Levy (Eds.), Oxford handbook of political psychology (2nd ed., pp. 852889). Oxford: Oxford University Press.

Guimond, S., de la Sablonnière, R., \& Nugier, A. (2014). Living in a multicultural world: Intergroup ideologies and the societal context of intergroup relations. European Review of Social Psychology, 25, 142-188. http://doi.org/10.1080/10463283.2014.957578

Hornsey, M. J., \& Jetten, J. (2004). The individual within the group: Balancing the need to belong with the need to be different. Personality and Social Psychology Review, 8, 220247. http://doi.org/10.1207/s15327957pspr0803

Iacoviello, V., \& Lorenzi-Cioldi, F. (2015). Individualistic tendencies: When group status makes the difference. Group Processes and Intergroup Relations, 18, 540-556. http://doi.org/10.1177/1368430214552332

Jetten, J., Mols, F., \& Postmes, T. (2015). Relative deprivation and relative wealth enhances anti-immigrant sentiments: The v-curve re-examined. PLoS ONE, 10, 1-24. http://doi.org/10.1371/journal.pone.0139156

Joppke, C. (2017). Civic integration in Western Europe: three debates. West European Politics, 40, 1153-1176. http://doi.org/10.1080/01402382.2017.1303252

Koopmans, R. (2010). Tradeoffs between equality and difference: Immigrant integration, multiculturalism, and the welfare state in cross-national perspective. Journal of Ethnic and Migration Studies, 36, 1-26. http://doi.org/10.1080/13691830903250881

Kukathas, C. (2003). The liberal archipelago: A theory of diversity and freedom. Oxford, UK: Oxford University Press. 
Kymlicka, W. (1995). Multicultural citizenship. Oxford, UK: Clarendon.

Kymlicka, W. (2001). Politics in the vernacular: Nationalism, multiculturalism and citizenship. Oxford: Oxford University Press.

Leach, C. W., Iyer, A., \& Pedersen, A. (2006). Anger and guilt about ingroup advantage explain the willingness for political action. Personality \& Social Psychology Bulletin, 32, 1232-1245. http://doi.org/10.1177/0146167206289729

Lesinska, M. (2014). The European backlash against immigration and multiculturalism. Journal of Sociology, 50, 37-50. http://doi.org/10.1177/1440783314522189

Lorenzi-Cioldi, F. (1998). Group Status and Perceptions of Homogeneity. European Review of Social Psychology, 9, 31-75. http://doi.org/10.1080/14792779843000045

MacIntyre, A. (1981). After virtue: A study in moral theory. London: Duckworth.

Mahfud, Y., Badea, C., Verkuyten, M., \& Reynolds, K. (2017). Multiculturalism and attitudes toward immigrants: The impact of perceived cultural distance. Journal of Cross-Cultural Psychology. http://doi.org/10.1177/0022022117730828

Major, B., Gramzow, R. H., McCoy, S. K., Levin, S., Schmader, T., \& Sidanius, J. (2002). Perceiving personal discrimination: The role of group status and legitimizing ideology. Journal of Personality and Social Psychology, 82, 269-282. http://doi.org/10.1037//0022-3514.82.3.269

Manatschal, A. (2011). Taking cantonal variations of integration policy seriously-Or how to validate international concepts at the subnational comparative level. Swiss Political Science Review, 17, 336-357. http://doi.org/10.1111/j.1662-6370.2011.02027.x

McCoy, S. K., \& Major, B. (2007). Priming meritocracy and the psychological justification of inequality. Journal of Experimental Social Psychology, 43, 341-351. http://doi.org/10.1016/j.jesp.2006.04.009

Meuleman, R., Bekhuis, H., Lubbers, M., \& Scheepers, P. (2013). Own culture first? 
Nationalism and the preference for national cultural goods. International Journal of Public Opinion Research, 25, 436-458. http://doi.org/10.1093/ijpor/eds024

Moghaddam, F. M. (2008). Multiculturalism and intergroup relations: Psychological implications for democracy in global context. Washington DC, US: American Psychological Association.

Morrison, K. R., Plaut, V. C., \& Ybarra, O. (2010). Predicting whether multiculturalism positively or negatively influences White Americans' intergroup attitudes: the role of ethnic identification. Personality \& Social Psychology Bulletin, 36, 1648-61. http://doi.org/10.1177/0146167210386118

Moscovici, S., \& Pérez, J. A. (2007). A study of minorities as victims. European Journal of Social Psychology, 37, 725-746. http://doi.org/https://doi.org/10.1002/ejsp.388

Mouffe, C. (1992). Dimensions of Radical Democracy: Pluralism, Citizenship and Community. London: Routledge.

Nunnally, J., \& Bernstein, I. (1994). Psychometric theory. New York: McGraw-Hill.

Plaut, V. C., Thomas, K. M., Hurd, K., \& Romano, C. A. (2018). Do color blindness and multiculturalism remedy or foster discrimination and racism? Current Directions in Psychological Science, 27, 200-206. http://doi.org/10.1177/0963721418766068

Powell, A. A., Branscombe, N. R., \& Schmitt, M. T. (2005). Inequality as ingroup privilege or outgroup disadvantage: The impact of group focus on collective guilt and interracial attitudes. Personality \& Social Psychology Bulletin, 31, 508-521. http://doi.org/10.1177/0146167204271713

Rawls, J. (1971). A theory of justice. Cambridge, MA: Harvard University Press.

Ross, L. (1977). The intuitive psychologist and his shortcomings: Distortions in the attribution process. In L. Berkowitz (Ed.), Advances in experimental social psychology (pp. 173-220). New York: Academic Press. 
Ryan, C. S., Hunt, J. S., Weible, J. a., Peterson, C. R., \& Casas, J. F. (2007). Multicultural and colorblind ideology, stereotypes, and ethnocentrism among black and white americans. Group Processes \& Intergroup Relations, 10, 617-637. http://doi.org/10.1177/1368430207084105

Sachdev, I., \& Bourhis, R. Y. (1991). Power and status differentials in minority and majority group relations. European Journal of Social Psychology, 21, 1-24.

http://doi.org/10.1002/ejsp.2420210102

Sampson, E. E. (1988). The debate on individualism: Indigenous psychologies of the individual and their role in personal and societal functioning. American Psychologist, 43, 15-22. http://doi.org/10.1037/0003-066X.43.1.15

Sandel, M. (1982). Liberalism and the limits of justice. Cambridge: Cambridge University Press.

Sears, D. O., Citrin, J., Cheleden, S. V., \& van Laar, C. (1999). Cultural diversity and multiculturalism: Is ethnic balkanization psychologically inevitable? In D. A. Prentice \& D. T. Miller (Eds.), Cultural divides: Understanding and overcoming group conflict (pp. 35-79). New York: Russell Sage Foundation.

Sidanius, J., \& Pratto, F. (1999). Social dominance: An intergroup theory of social hierarchy and oppression. Cambridge, UK: Cambridge University Press.

Simon, B. (2011). Identity and participation in culturally diverse societies. In A. E. Azzi, X. Chryssochoou, B. Klandermans, \& B. Simon (Eds.), Identity and participation in culturally diverse societies (pp. 137-157). Oxford, UK: Blackwell Wiley.

Simon, B., Aufderheide, B., \& Kampmeier, C. (2001). The social psychology of minoritymajority relations. In R. Brown \& S. Gaertner (Eds.), Blackwell handbook of social psychology: Intergroup processes (pp. 303-323). Malden, MA: Blackwell.

Simon, B., \& Oakes, P. J. (2006). Beyond dependence: An identity approach to social power 
and domination. Human Relations, 59, 105-139.

http://doi.org/10.1177/0018726706062760

Simon, B., \& Ruhs, D. (2008). Identity and politicization among Turkish migrants in Germany: The role of dual identification. Journal of Personality and Social Psychology, 95, 1354-1366. http://doi.org/10.1037/a0012630

Son Hing, L. S., Bobocel, D. R., Zanna, M. P., Garcia, D. M., Gee, S. S., \& Orazietti, K. (2011). The merit of meritocracy. Journal of Personality and Social Psychology, 101, 433-450. http://doi.org/10.1037/a0024618

Staerklé, C. (2009). Policy attitudes, ideological values and social representations. Social and Personality Psychology Compass, 3, 1096-1112. http://doi.org/10.1111/j.17519004.2009.00237.x

Staerklé, C., \& Green, E. G. T. (2018). Right-wing populism as a social representation: A comparison across four European countries. Journal of Community \& Applied Social Psychology, 28, 430-445. http://doi.org/10.1002/casp.2369

Świątkowski, W., \& Dompnier, B. (2017). Replicability crisis in social psychology: Looking at the past to find new pathways for the future. International Review of Social Psychology, 30, 111-124.

Taylor, C. (1985). Philosophy and the human sciences: Philosophical papers 2. Cambridge: Cambridge University Press.

Tyler, T. R., \& van der Toorn, J. (2013). Social justice. In L. Huddy, D. O. Sears, \& J. S. Levy (Eds.), Oxford handbook of political psychology (2nd ed., pp. 627-661). Oxford: Oxford University Press.

van de Vijver, F. J. R., Breugelmans, S. M., \& Schalk-Soekar, S. R. G. (2008). Multiculturalism: Construct validity and stability. International Journal of Intercultural Relations, 32, 93-104. http://doi.org/10.1016/j.ijintrel.2007.11.001 
Verkuyten, M. (2005). Ethnic group identification and group evaluation among minority and majority groups: testing the multiculturalism hypothesis. Journal of Personality and Social Psychology, 88, 121-38. http://doi.org/10.1037/0022-3514.88.1.121

Verkuyten, M. (2006). Multicultural recognition and ethnic minority rights: A social identity perspective. European Review of Social Psychology, 17, 148-184. http://doi.org/10.1080/10463280600937418

Verkuyten, M., \& Martinovic, B. (2006). Understanding multicultural attitudes: The role of group status, identification, friendships, and justifying ideologies. International Journal of Intercultural Relations, 30, 1-18. http://doi.org/10.1016/j.ijintrel.2005.05.015

Viechtbauer, W. (2010). Conducting meta-analysis in R with the metafor package. Journal of Statistical Software, 36, 1-48. http://doi.org/10.18637/jss.v036.i03

Walzer, M. (1990). The communitarian critique of liberalism. Political Theory, 18, 6-23.

Wiley, S., Deaux, K., \& Hagelskamp, C. (2012). Born in the USA: How immigrant generation shapes meritocracy and its relation to ethnic identity and collective action. Cultural Diversity and Ethnic Minority Psychology, 18, 171-180. http://doi.org/10.1037/a0027661

Wolsko, C., Park, B., \& Judd, C. M. (2006). Considering the tower of babel: Correlates of assimilation and multiculturalism among ethnic minority and majority groups in the United States. Social Justice Research, 19, 277-306. http://doi.org/10.1007/s11211-0060014-8

Yogeeswaran, K., \& Dasgupta, N. (2014). The devil is in the details: Abstract versus concrete construals of multiculturalism differentially impact intergroup relations. Journal of Personality and Social Psychology, 106, 772-89. http://doi.org/10.1037/a0035830

Zárate, M. A., Shaw, M., Marquez, J. A., \& Biagas, D. (2012). Cultural inertia: The effects of cultural change on intergroup relations and the self-concept. Journal of Experimental 
Social Psychology, 48, 634-645. http://doi.org/10.1016/j.jesp.2011.12.014 